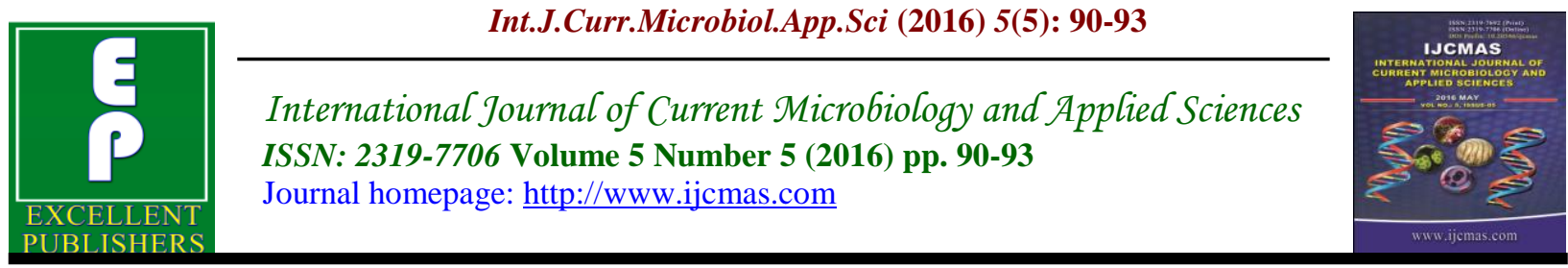

Original Research Article

http://dx.doi.org/10.20546/ijcmas.2016.505.010

\title{
A Study on Soil Palynomorph Diversity of an area in Kolkata, India
}

\author{
Roy Debleena*, Hazra Gargi, Sinha Suchita, Saha Rinku and Mallick Bidisha \\ Department of Botany, Lady Brabourne College, Kolkata, WestBengal, India \\ *Corresponding author
}

\section{Keywords}

Palaeopalynology,

Palaeovegetation,

Palaeoclimate,

Late-Quaternary,

Brackish

and fresh water

environment,

Mangrove,

Humidity,

Sunderbans.

\section{Article Info}

Accepted:

08 April 2016

Available Online:

10 May 2016
A B S T R A C T

Palaeopalynological study was conducted in relation to reconstruct the palaeovegetation and palaeo climatic condition of our college area. For this purpose samples were collected from Lady Brabourne College premises, Park Circus [central-east zone of Kolkata] area. Our present study reveals the deposition age nearly from 7000-2000 yrs BP, confirming the Late-Quaternary age of the samples. At lower layer (40 ft), sample reveals vegetation as open grassland type. Presence of grass pollen, fern spores along with Heritiera and palms in little amount were recorded. Occurrence of Typha pollen indicates marshy habitat. Middle layer (33$27 \mathrm{ft}$ ) unfolds a mixed forest type including Heritiera, Suaeda, and grass pollen indicating the transition from saline to fresh water environment. At upper layer (23$19 \mathrm{ft}$ ), Heritiera was uniformly present along with fern spores, Suaeda, grass pollen etc. So the present study unfolds that mangrove vegetation was dominated in this region during Late-quaternary period. Occurrence of grass pollen throughout the strata indicates the prevalence of equable temperature and also human interference in the investigated area. Presence of various types of fungal spores throughout the strata indicates that the climatic condition was tropical with high humidity. Deposition of peat layers indicates strong and extensive river discharges which coincides with the intensification of monsoonal rainfall at summer. Environment was mixed type with brackish \& fresh water because floral vegetation was regular inundated with sea water. Due to salinity in water source, water supply of plants was mostly from soil moisture. So, it is assumed that, before 2000 yrs Kolkata was a part of Sunderbans.

\section{Introduction}

Lady Brabourne College campus is situated in Park Circus, central-east part of Kolkata. The College campus is green and flourished with diverse vegetation. Plant groups include bryophytes, pteridophytes, some gymnosperms and majority belongs to angiosperms of mesophytic type growing on terrestrial land.
Pollen and spores are produced by plants in a large amount. Excess pollen and spores settle to soil, from there they are washed away in water bodies. Humification occurs and in favourable environment they become fossilized and remain in sediments for long years without any desiccation. This is due to the presence of sporopollenin in their exine which is very inert compound and can resist chemical attacks. Every year new sediment 
layer is formed and pollen record is trapped there. This property helps them to serve as evidence of past vegetation. Previous reports on past vegetation of Kolkata revealed that mangrove flora was dominated in Kolkata during late-Quaternary period which now a days is dominant in Sunderbans, situated at southern part of West Bengal (Barui and Chanda 1992). In our current project we are trying to trace the past vegetation type of our college campus dominated during lateQuaternary period from palynomorph study. A typical vegetation type depends on typical climatic condition, so by tracing palaeovegetation, we will be able to know the past climatic condition also.

\section{Materials and Methods}

A bore hole of $400 \mathrm{ft}$ depth was made at the north of college campus. From that hole we have collected sediment deposits of different heights from bottom to top layer at $10 \mathrm{ft}$ intervals. The samples were treated with $10 \% \mathrm{KOH}$ to remove humus. Then $\mathrm{HCL}$ was added then to remove bicarbonate. After that $40 \% \mathrm{HF}$ was added and kept overnight to dissolve siliceous particles present in the sample. Finally acetolysis was done to stain pollen grain \& spores. After chemical treatment, slides were prepared in poly vinyl alcohol for extensive microscopic study.

\section{Results and Discussion}

Sample of lower layer (40 ft) reveals several kinds of fungal spores that are different in size, shape, wall thickening etc (Fig 1). Pollen grain of grass origin is in high amount and some monosulcate apertural grains were identified those indicating palms (Phoenix paludosa) (Fig 3A). Fern spores like Lygodium, Ceratopteris were observed which are significant as they are not available now a days in our area of study. Typha pollen grains were sparsely present throughout the stratum indicating marshy habitat (Fig 3E). Chenopodiaceous grains were also recorded. At the topmost zone of this stratum Heritiera pollen grains were observed. Along with this some grains of palms, Excoecaria also recorded. At middle later (30 ft) also fungal spores with different morphology were recorded. Typical fern spores (triangular in shape with trilete aperture) noticed. Fern spores were recorded at lower part of this stratum, but absent in upper part (Fig 2).

Fig.1 Fungal Spore

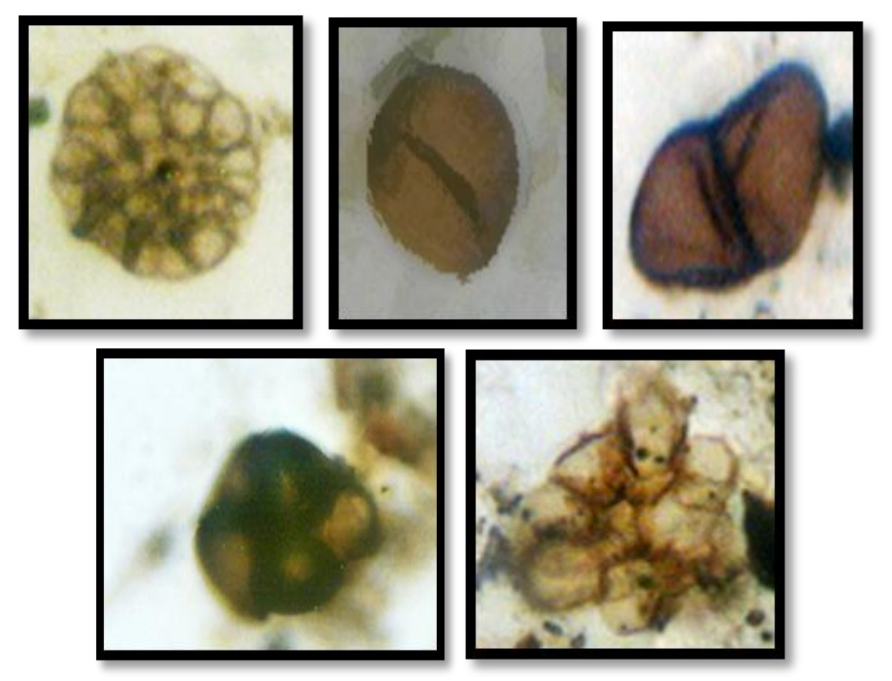


Fig.2 Fern Spore
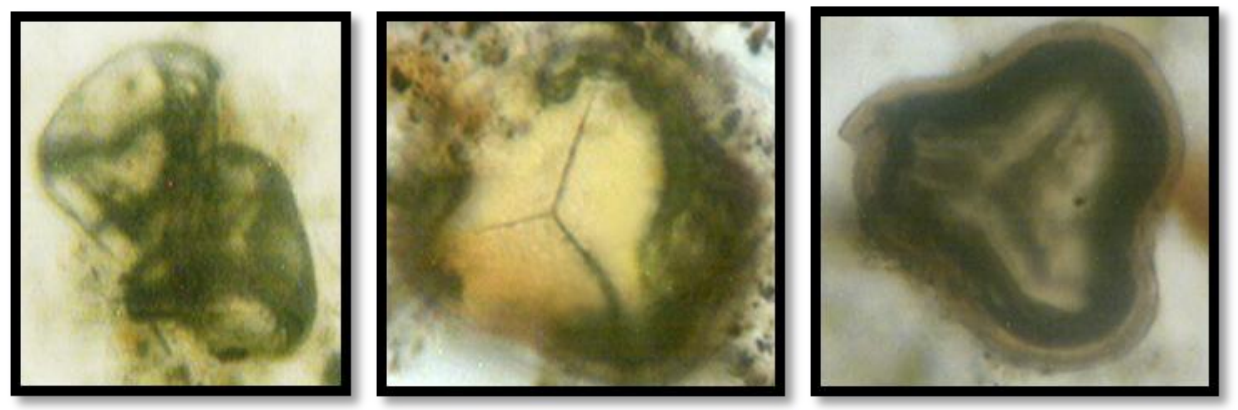

Fig.3 A. Phoenix, B. Pteris, C. Pteridium, D. Suaeda, E. Typha

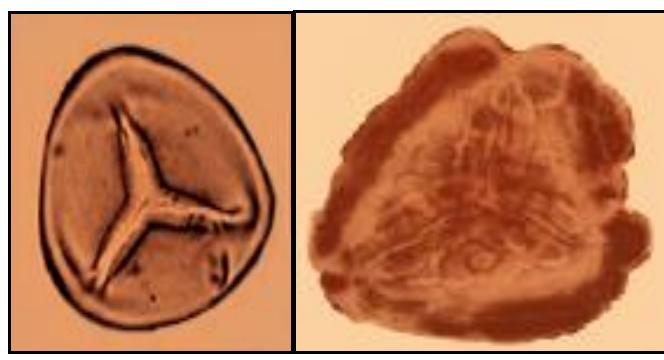

A
B

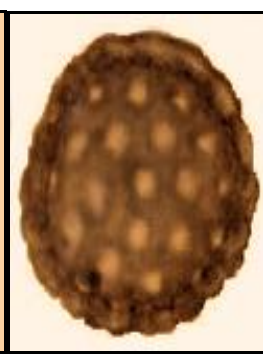

$\mathrm{C}$

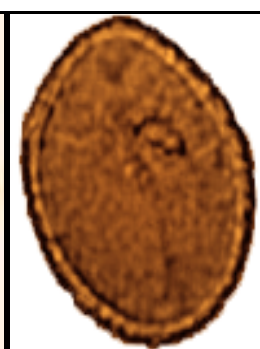

D

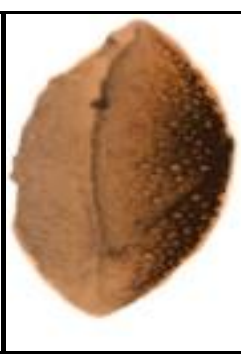

E
This sediment layer reveals more or less uniform vegetation type. Pollen grains of arboreal and non-arboreal plants were identified. In arboreal type, Heritiera, Phoenix was identified. In several zone of this layer Heritiera and Barringtonia pollen grains were identified indicating mixed forested condition. This stratum reveals uniform occurrence of Heritiera pollen grain. During deposition of this stratum Heritiera was dominant at this area. At upper layer $(10 \mathrm{ft})$ huge occurrence of fungal spores was recorded in this stratum like the previous strata. Bottom zone of this layer is dominated by pollen grains of nonarboreal flora (grasses). Other than grasses, Heritiera, Phoenix pollen grains were identified. Thus bottom zone indicates a mixed vegetation type. In uppermost zone of this layer, pollen of Heritiera \& Excoecaria were recorded in maximum number. Fern spores were sparsely present. This zone indicates a forested condition. Sediment deposition age was found to be 7000-2000 years before present (from $40-10 \mathrm{ft}$ ).

From palaeopalynological study, we can state that in our college campus the vegetational type during late-Quaternary was totally different from todays. Halophytic plant groups, fern of marshy land were dominant during that period at our campus. The palynomorph assemblage indicates a composition of halophytic plants mixed with ferns and some fresh water angiosperm members. Among halophytes major genera include Heritiera, Excoecaria, Barringtonia, Phoenix, and members of chenopodiaceae family. Pollen grains of grasses were huge in occurrence and Typha pollen was recorded. By studying palaeovegetation, it has been found that mangrove vegetation was dominant at our college campus, so climatic condition during that period could be easily comparable with the present climate of Sunderbans, tropical 
with high humidity. The vegetation we have found is mixed type of salt \& fresh water environment similar to that of today's Sunderbans (Banerjee and Sen 1987). Sunderban is a land at Ganges delta where mixing of fresh water coming from rivers and saline water occurs. The land is inundated during tide by sea water. This condition also occurred at our study area during late-Quaternary period. During rainy season freshwater plumes from river pushed the intruding saltwater out and brought a deposition of slit. Thus sediment layers were formed year after year. Presence of huge fungal spores throughout the strata indicates the occurrence of humid condition because many soil inhabiting fungus grow well in humid climate. We have also observed more or less uniform occurrence of grass pollen grains those indicate equable temperature like today's and also indicates interference of human activity. Continuous river slitting, sea transgression, increase in population have shifted the mangrove vegetation towards south of West Bengal where Sunderbans is situated (Das 2009). Increased human population have increased paddy cultivation land acquisition, non-sustainable utilization of plant products have reduced mangrove vegetation.

It can easily be concluded that our college campus was flourished with mangrove vegetation during late-Quaternary period that is totally different from today's mesophytic vegetation.

\section{Acknowledgement}

The authors are thankful for financial assistance from DBT, under the DBT Star college scheme, Department of Botany, Lady Brabourne College, Kolkata. Authors also acknowledge Professor Subir bera, Department of Botany, University of Calcutta.

\section{References}

Barui, N.C., Chanda, S. 1992. Latequaternary pollen analysis in relation to palaeoecology, biostratigraphy \& dating of Calcutta peat. Proc. Nat. Acad. Sci., pp 191-200.

Banerjee, M., Sen, P.K. 1987. Paleobiology in understanding the change of sea level and coastline in Bengal Basin during Holocene period. Indian J. Earth Sci., Pp 307-320.

Das, S. 2009. Palaeoecology of the lower Bengal basin, Calcutta, India, during the late-quaternary. Feddes Repertorium, pp 333-342.

\section{How to cite this article:}

Roy Debleena, Hazra Gargi, Sinha Suchita, Saha Rinku and Mallick Bidisha. 2016. A Study on Soil Palynomorph Diversity of an area in Kolkata, India. Int.J.Curr.Microbiol.App.Sci. 5(5): 90-93. doi: http://dx.doi.org/10.20546/ijcmas.2016.505.010 